\title{
Brief communication: 3-D reconstruction of a collapsed rock pillar from Web-retrieved images and terrestrial lidar data - the 2005 event of the west face of the Drus (Mont Blanc massif)
}

\author{
Antoine Guerin ${ }^{1}$, Antonio Abellán ${ }^{2}$, Battista Matasci $^{3}$, Michel Jaboyedoff ${ }^{1}$, Marc-Henri Derron ${ }^{1}$, and \\ Ludovic Ravanel ${ }^{4}$ \\ ${ }^{1}$ Risk Analysis Group, Institute of Earth Sciences, University of Lausanne, Lausanne, Switzerland \\ ${ }^{2}$ Scott Polar Research Institute, University of Cambridge, Cambridge, UK \\ ${ }^{3}$ Bureau d'Etudes Géologiques SA, Aproz, Switzerland \\ ${ }^{4}$ EDYTEM, University Savoie Mont Blanc - CNRS, Le Bourget du Lac, France
}

Correspondence to: Antoine Guerin (antoine.guerin@unil.ch)

Received: 27 September 2016 - Discussion started: 7 October 2016

Revised: 6 June 2017 - Accepted: 12 June 2017 - Published: 18 July 2017

\begin{abstract}
In June 2005, a series of major rockfall events completely wiped out the Bonatti Pillar located in the legendary Drus west face (Mont Blanc massif, France). Terrestrial lidar scans of the west face were acquired after this event, but no pre-event point cloud is available. Thus, in order to reconstruct the volume and the shape of the collapsed blocks, a 3-D model has been built using photogrammetry (structure-from-motion (SfM) algorithms) based on 30 pictures collected on the Web. All these pictures were taken between September 2003 and May 2005. We then reconstructed the shape and volume of the fallen compartment by comparing the SfM model with terrestrial lidar data acquired in October 2005 and November 2011. The volume is calculated to $292680 \mathrm{~m}^{3}( \pm 5.6 \%)$. This result is close to the value previously assessed by Ravanel and Deline (2008) for this same rock avalanche $\left(265000 \pm 10000 \mathrm{~m}^{3}\right)$. The difference between these two estimations can be explained by the rounded shape of the volume determined by photogrammetry, which may lead to a volume overestimation. However it is not excluded that the volume calculated by Ravanel and Deline (2008) is slightly underestimated, the thickness of the blocks having been assessed manually from historical photographs.
\end{abstract}

\section{Introduction}

The Drus (3754 m a.s.l.) is a mountain with emblematic summits of the Chamonix valley situated in the Mont Blanc massif (France). Since the middle of last century, the Petit Dru west face ( $1000 \mathrm{~m}$ high, $3730 \mathrm{~m}$ a.s.l.) has been affected by intense erosion which has significantly modified the morphology of this peak (Ravanel and Deline, 2006, 2008; Fort et al., 2009). In June 2005, a rock pillar (the Bonatti Pillar) estimated to be around $265000 \pm 10000 \mathrm{~m}^{3}$ by Ravanel and Deline (2008), collapsed, destroying forever numerous climbing routes. The assessment of this volume by Ravanel and Deline (2008) was performed in two steps: (a) identification in photos of different rock elements (slabs, dihedrons, overhangs) whose dimensions (height, width, depth) can be compared with compartments now collapsed and (b) measurements of these dimensions on terrestrial lidar scans acquired just after the event in October 2005. Historical photographs of the west face taken from different viewpoints facilitate the estimation of the thickness of the missing elements, which remains the most difficult dimension to determine. Under this method, the assessment of rock thickness ( $8 \mathrm{~m}$ on average) represents the greatest source of uncertainty since the height and width of the rock avalanche scar could be very accurately measured based on the October 2005 lidar data. Note that these lidar scans correspond to the oldest reference, and no 3-D model is available before the major event of June 2005. Thus, in order to get the pre-event topography of the Petit 
Dru west face, we collected several pictures dating from 2003 to 2005 from different online picture-hosting services, and a 3-D photogrammetric model was reconstructed. Such an approach has already been used in different research areas, such as cultural heritage conservation: a precursor of this "crowdsourced" technics, Grün et al. $(2004,2005)$ reproduced in 3$\mathrm{D}$ the statue of the Great Buddha of Bamiyan (Afghanistan) using a series of pictures obtained from the Internet. More recently, many historians, archaeologists and architects (e.g., Furukawa et al., 2010; Doulamis et al., 2013; Ioannides et al., 2013; Kyriakaki et al., 2014; Santos et al., 2014) have taken advantage of the large amount of images available online to preserve and keep a digital record of cultural and historical heritage using structure-from-motion (SfM) algorithms (Snavely et al., 2008). According to the New York Times (Estrin, 2012), over 380 million pictures are uploaded on Facebook every day, and other authors such as Stathopoulou et al. (2015) or Vincent et al. (2015) have used crowdsourced imagery to virtually replicate heritage objects destroyed by natural disasters, armed conflict or terrorism. Examples include the stone bridge of Plaka (Greece), the city of Kathmandu before and after the 2015 earthquake and several artworks at the Mosul Museum (Iraq).

In geosciences, conventional photogrammetry has long been used for digital elevation model (DEM) generation, but it is only recently that SfM has popularized the use of 3-D point clouds in this field (e.g., Firpo et al., 2011; Salvini et al., 2013; James and Robson, 2014; Lucieer et al., 2014). The review conducted by Eltner et al. (2016) shows that the annual number of publications that refer to SfM has really exploded since 2014, particularly in the fields of soil erosion, glaciology and fluvial morphology. This method is surprisingly straightforward to implement and also relatively accurate when compared to other techniques such as groundbased lidar data. In 2013, Fonstad et al. (2013) obtained differences of about $0.1 \mathrm{~m}$ (in $X, Y$ and $Z$ ) between these two methods. In addition, new technologies such as unmanned aerial vehicles (UAVs) combined with SfM have modernized and revolutionized investigations on several Earth surface phenomena (Abellán et al., 2016; Smith et al., 2016). For instance, Turner et al. (2012) and Lucieer et al. (2014) obtained $4 \mathrm{~cm}$ errors when comparing DEMs from UAV-SfM to differential Global Positioning System (dGPS) ground control points. In 2016, Bakker and Lane (2016) innovated by showing the potential to couple archival aerial photographs and SfM algorithms to quantify morphological changes in a river-floodplain system at a decadal scale. However, despite all these recent advances, paleotopographic reconstruction based on old terrestrial images or orthophotos has rarely been used in the field of geohazards to improve erosion rate quantification (Oikonomidis et al., 2016). For this reason, the aim of this brief communication is to illustrate the potential to merge ground-based lidar measurements with terrestrial SfM point clouds made from publicly available images. This allows traveling back in time in order to better quantify past natural disasters. More specifically, this short note reports the results of the 3-D reconstruction of the Drus west face before the Bonatti Pillar collapse in June 2005.

\section{Geological and structural setting}

From a geological point of view, the Mont Blanc crystalline range describes a broad ellipse elongated in the NE-SW direction extending from the Val Ferret (Valais, Switzerland) to the Chapieux valley (Savoie, France) (Fig. 1a). The central part of the massif develops in the Aosta valley (Italy) and Haute-Savoie (France), and it consists of two major petrological units: plutonic rocks (granites), mainly, and metamorphic rocks (gneiss and mica schists) which merge near the summit of Mont Blanc (Fig. 1a and b). From southwest to northeast, granite moves from an intrusive position in gneiss to a tectonic contact materialized by the faille de l'Angle ("de l'Angle fault", Fig. 1b) (Epard, 1990). This fault separates the Mont Blanc massif into two sections: an internal part that is essentially granitic and a more metamorphic external part (Epard, 1990; Steck et al., 2000, 2001). The Petit Dru west face presents a coarse-grained calc-alkaline granite, which was formed during the Hercynian orogeny and dated from $305 \pm 2$ million years (Bussy et al., 1989; von Raumer and Bussy, 2004; Egli and Mancktelow, 2013). The steep rock cliff (average dip angle of $75^{\circ}$ ) is cut by a set of two large sub-vertical fractures oriented $238^{\circ} / 85^{\circ}$ and $303^{\circ} / 79^{\circ}$ which form wedges and by four other joint sets (especially $106^{\circ} / 33^{\circ}$ ) which form deep overhangs (Ravanel and Deline, 2008; Matasci et al., 2015). These very persistent dihedral structures (mean trace length of $80 \mathrm{~m}$ ) promote the collapse of large compartments and played a major role (Matasci et al., 2015) during the large rockfall events of summer 2005 and fall 2011 (Fig. 1c).

\section{Material and methods}

The 3-D reconstruction of the Drus west face was carried out using 30 Web-retrieved images from different picturehosting services (Flickr.com, SummitPost.org and Camptocamp.org; see Appendix A) and a commercial photogrammetric (Agisoft PhotoScan, 2014) software (version 1.0.3). The georeferencing-alignment procedure of point clouds was done with CloudCompare (Girardeau-Montaut, 2015) software (version 2.7.0), and an estimation of the missing volume was then performed using 3DReshaper (Technodigit, 2014) software (2014 MR1 version) by comparing the SfM point cloud with terrestrial lidar scans acquired after the event.

\subsection{Selection of photographs from the Internet}

Before the 30 June 2005 rock avalanche, the Drus west face was affected by major rockfalls in September 1997 $\left(27500 \pm 2500 \mathrm{~m}^{3} ; 17-18\right.$ and 28 September) and August 


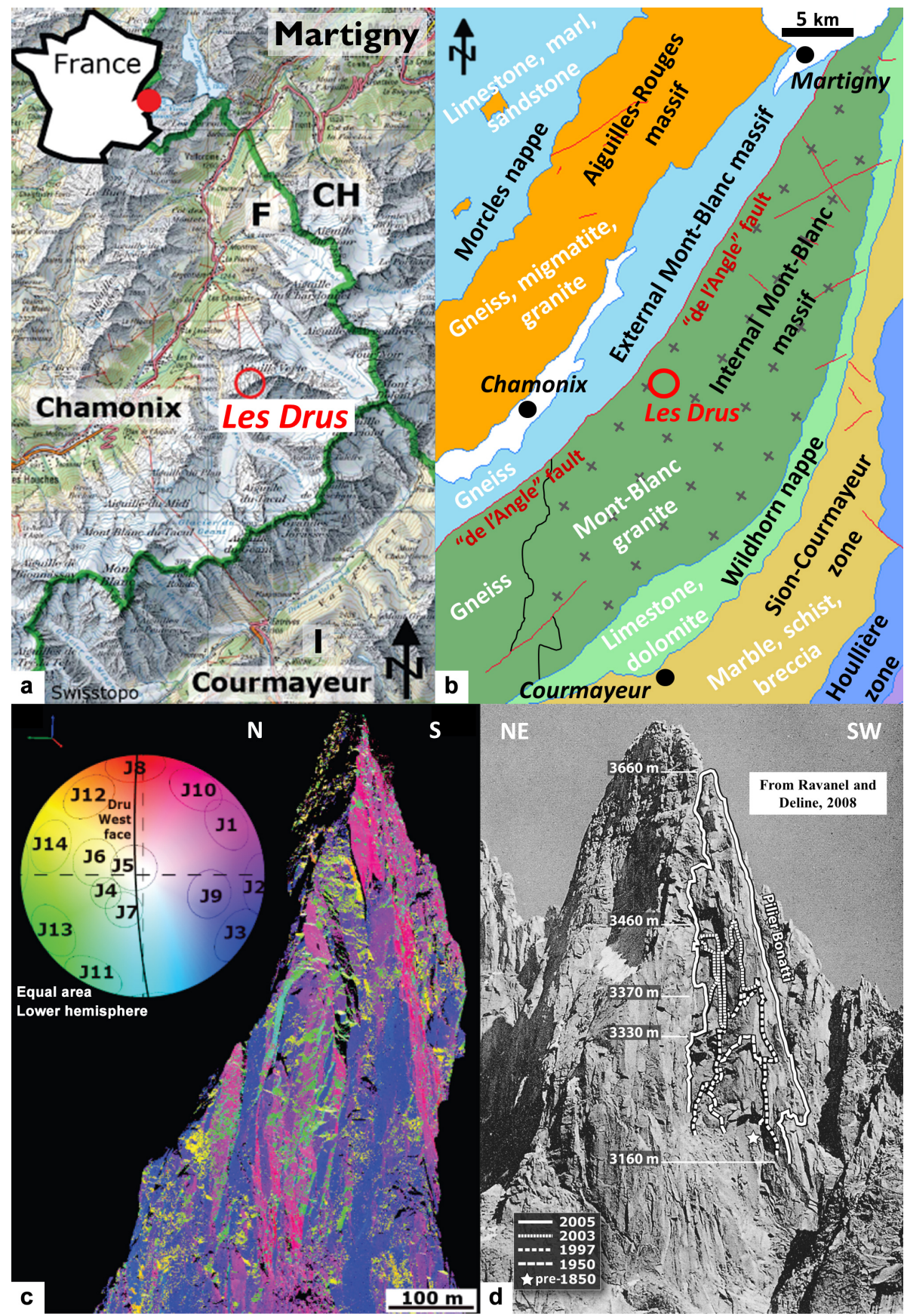

Figure 1. Location and geological setting of the study area. (a) Location of the Drus within the Chamonix valley (Mont Blanc massif, France); background map: Swisstopo. (b) Geotectonic map of the study area (map modified after Steck et al., 2000). (c) 2005/2011 merged lidar point cloud and discontinuities measured in the Drus west face. Each color corresponds to the stereographic projection of the poles of joint sets (Schmidt stereonet, Coltop3D software). (d) Photo-comparison reconstruction of the main historical rockfall events that occurred on the Drus west face from 1850 onwards (figure modified after Ravanel and Deline, 2008).

$2003\left(6500 \pm 500 \mathrm{~m}^{3} ; 2-3\right.$ August) (Ravanel and Deline, 2008). These events significantly modified the morphology of the pillar between 3160 and $3460 \mathrm{~m}$ a.s.l. (Fig. 1d), and we thus looked for photographs taken between early $\mathrm{Au}$ gust 2003 and the end of June 2005. This was carried out by looking at the Exif metadata which are publicly available within the three abovementioned imagery repositories. After a visual check, 30 pictures taken from different viewpoints and with a mean size of 500 Ko were selected (Fig. 2 and Appendix A). Note that, due to a limited number of available 


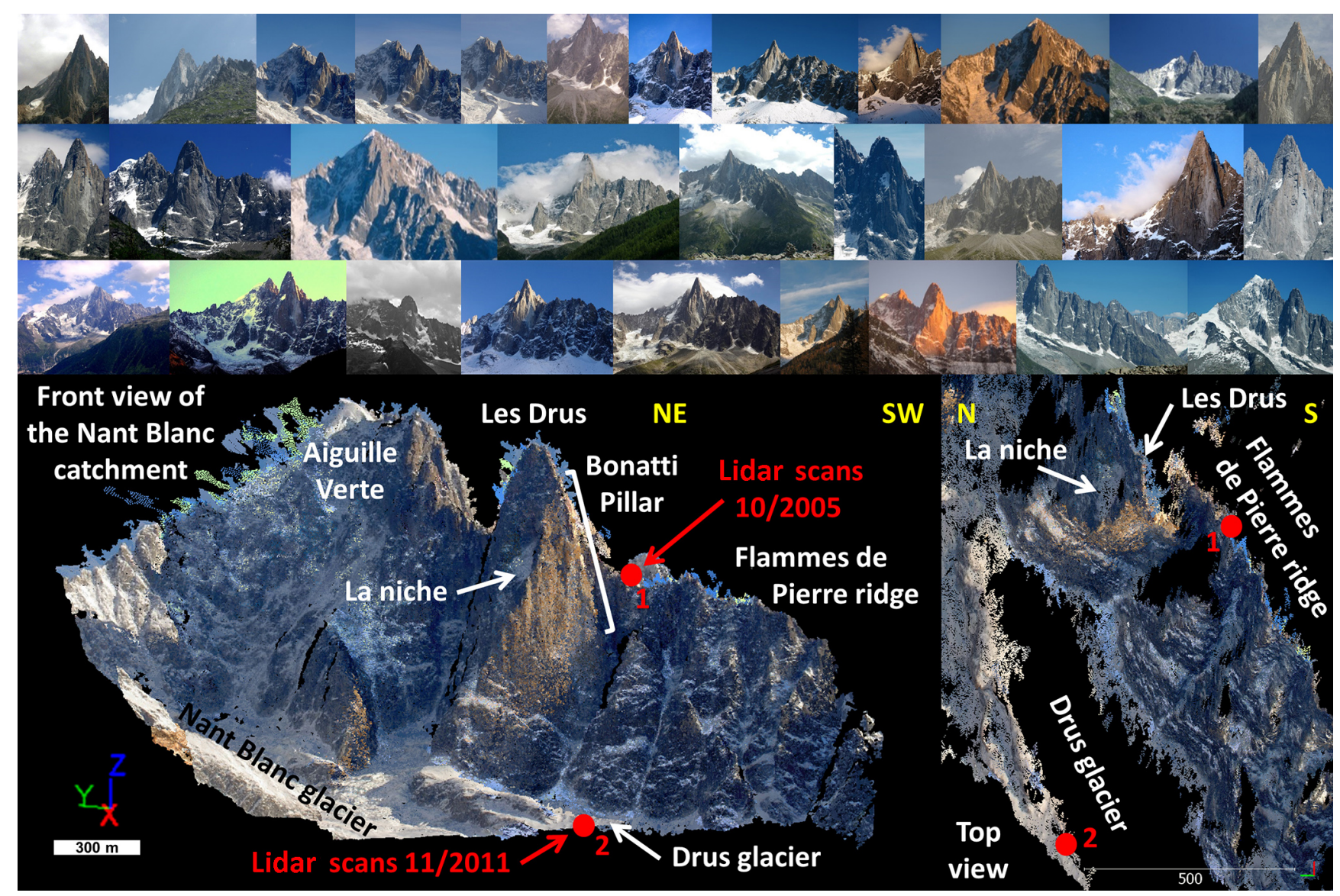

Figure 2. Catalogue of the 30 pictures selected on the Internet (upper part; photo credits, citations and links available in Appendix A) and used to reconstruct the northwestern side (the Nant Blanc catchment) of the Aiguille Verte and Drus (lower part, front view and top view of the SfM point cloud) before the Bonatti Pillar collapse in June 2005. Both red dots show the location of the 2005 and 2011 ground-based lidar acquisitions.

images, we were forced to choose pictures taken in different seasons. However, in winter, snow is hardly present on the steep Drus faces, and, except at the foot of the cliff, there is no snow in the area of interest of the Bonatti Pillar in the 30 selected images (Fig. 2).

\subsection{Ground-based lidar data acquisition}

In order to obtain a 3-D model of the entire Drus west face with a high and homogeneous density of points ( $\sim 250$ points $\mathrm{m}^{-2}$, i.e., 1 point every $6.2 \mathrm{~cm}$ ), we merged the lidar scans from two different measurement campaigns carried out in October 2005 and November 2011. The 2005 point cloud (assembly of three scans, 7.5 million points) represent only the upper part of the face and was acquired from the Flammes de Pierre ridge (Fig. 2) with a mediumrange laser scanner (Optech ILRIS-3-D) (Ravanel and Deline, 2006). The 2011 point cloud (assembly of three scans, 24 million points) of the whole face has been acquired with a long-range laser scanner (Optech ILRIS-LR) from the right lateral moraine of the Drus glacier, situated around $2500 \mathrm{~m}$ a.s.1. (Fig. 2).

\subsection{Georeferencing and alignment of lidar scans}

In the absence of a fairly accurate DEM (the resolution of the IGN's DEM is only $30 \mathrm{~m}$ in this sector), both datasets were georeferenced using the scanner position measured by dGPS, then aligned with respect to the vertical axis using the coordinates of several points distributed in the cliff and measured with a total station. The scans were then aligned with each other using iterative closest point (ICP) algorithms (Besl and McKay, 1992) but only applied to stable parts (manually selected because of the different viewpoints) because between these two acquisitions two major rockfalls occurred in September $2011\left(4530 \pm 200 \mathrm{~m}^{3}\right)$ and October $2011\left(54730 \pm 400 \mathrm{~m}^{3}\right)$ in the June 2005 rock avalanche scar area (Fig. 6d). These volumes were determined by comparing the 2005 and 2011 lidar acquisitions and include the "small" rockfalls (range of volumes: $1-426 \mathrm{~m}^{3}$ ) detected between October 2005 and September 2008 by an annual li- 
dar monitoring carried out from the Flammes de Pierre ridge (Ravanel, 2010). The points belonging to all these rockfall events have therefore been removed from the merged cloud, and a volume of $59260 \mathrm{~m}^{3}$ is to be subtracted from the estimated volume for the Bonatti Pillar collapse, given by the result of the comparison between the pre- (SfM model) and post-event (2005/2011 merged and "cleaned" lidar point cloud).

\subsection{Construction and alignment of the SfM point cloud}

The workflow described by Smith et al. (2016) was used to construct a point cloud of the former Drus west face with Agisoft PhotoScan. All selected pictures were aligned during this procedure, and the final model (Fig. 2) that represents the northwestern side of the Aiguille Verte and Drus (Nant Blanc catchment) consists of 895300 points, with a mean density of 0.42 points $\mathrm{m}^{-2}$ (Fig. 3d). Note that in the Bonatti Pillar sector (the area of interest) this value is slightly higher and reaches a median value of 0.65 points $\mathrm{m}^{-2}$, and no ground control points were imposed when generating the 3-D model in Agisoft PhotoScan. The SfM point cloud was then roughly scaled and aligned on the 2005/2011 merged lidar point cloud by selecting several equivalent point pairs (a dozen) sufficiently distant from each other. After this, the SfM model was cut into 30 parts with an octree structure in order to accurately align and scale each portion independently on the lidar point cloud. As highlighted by Wujanz et al. (2016), ICP algorithms (Besl and McKay, 1992) were only applied to stable parts so as not to bias the comparison values detected in the Bonatti Pillar area. Furthermore, aligning and scaling each part independently compensates for the fact that no ground control points have been imposed in Agisoft PhotoScan. This procedure makes it possible to gradually deform the SfM cloud and to optimally adjust each section on the reference lidar point cloud. However, the overall shape of the SfM cloud is very wavy (Fig. 3d and f), and because of this the average deviation in the stable areas reaches $\pm 1.17 \mathrm{~m}$ (Fig. 3e).

\subsection{SfM-lidar comparison and rockfall extraction}

The first step to perform a point-to-mesh comparison was to transform the 2005/2011 merged lidar point cloud into a reference triangular mesh. All the points were used for the mesh generation, and a maximum length of triangle edge of $5 \mathrm{~m}$ was set to fill the existing holes in the point clouds (zones masked by the relief). Unlike the point-to-point comparison, the point-to-mesh comparison calculates the orthogonal distance between both entities, which corresponds to the shortest distance between a point and the nearest triangle. Figure 3a shows not only the result of this comparison but also the points (in red in Fig. 3b) that were extracted from the SfM cloud and associated with the Bonatti Pillar collapse. The point extraction was carried out on the basis of the method defined by Tonini and Abellán (2014). This method is illustrated in Fig. 4 and includes four steps: (a) definition of a level of detection ( $\mathrm{LoD} \pm 1.2 \mathrm{~m}$ in our case, in agreement with the average deviation observed in the stable areas) and three-color distribution of comparison values: red for positive deviations, green for the points between $\pm 1.2 \mathrm{~m}$ and blue for negative deviations (Fig. 4a); (b) color filtering to keep only the red points associated with positive deviations and in which the points associated with the Bonatti Pillar collapse are present (Fig. 4b and c); (c) noise reduction using the nearest-neighbor clutter removal algorithm (Byers and Raftery, 1998), which is based on the spatial density of points in 3-D; and (d) individualization of rockfalls with the DBSCAN algorithm (Ester et al., 1996), which uses a distance criterion to explode a cloud into a sub-group of clouds (Fig. 4d).

\subsection{Volume calculation}

We estimated the June 2005 rock avalanche volume by constructing a closed mesh. For this purpose, the points extracted from the SfM cloud were first converted into a triangular mesh (Fig. 5a-d) to generate a surface whose contour (the free border) has been extracted automatically (red contour in Fig. 5). However, unlike the lidar mesh, only a small part of the points of the extracted SfM cloud have been preserved for the generation of this second mesh. Indeed, we decided to subsample the SfM cloud and retain only 1 point out of 10 (Fig. 5b and c), and then to smooth the mesh obtained (Fig. 5d and 6d) in order to limit as far as possible the undulation effect highlighted in Sect. 2.4. This smoothing procedure is accompanied by an interpolation of new points and was first tested on the profile P2 located within the stable area framed in Fig. 3. Figure 6 shows that the smoothing makes it possible to generate a substantially less undulating profile that is thus much closer to the lidar profile. The dispersion diagram of Fig. 6c illustrates this aspect since the smoothing allows the large deviations to be minimized and the average deviation to be significantly reduced by $\pm 0.76 \mathrm{~m}$. When this correction factor is applied, the average deviation therefore changes from \pm 1.17 to $\pm 0.41 \mathrm{~m}$ in stable areas, final value used to define the uncertainty on the depth of the estimated volume.

The red contour (3-D polyline) of the smoothed mesh was then orthogonally projected onto the reference lidar mesh (Fig. 5e) in order to divide it into two parts and keep only the triangles located inside the projected contour (delimitation of the rockfall scar, Fig. $5 \mathrm{f}$ and g). The gap between both contours was filled by a third mesh, which corresponds to the thickness of the fallen volume (Fig. 5h). Finally, we merged these three surfaces to generate a closed mesh (Fig. 5i). The volume of the rockfall event is then given by the sum of the tetrahedrons volumes forming the closed mesh. In addition, in order to assess another error in the volume calculation but only related this time to the SfM method itself, we created 


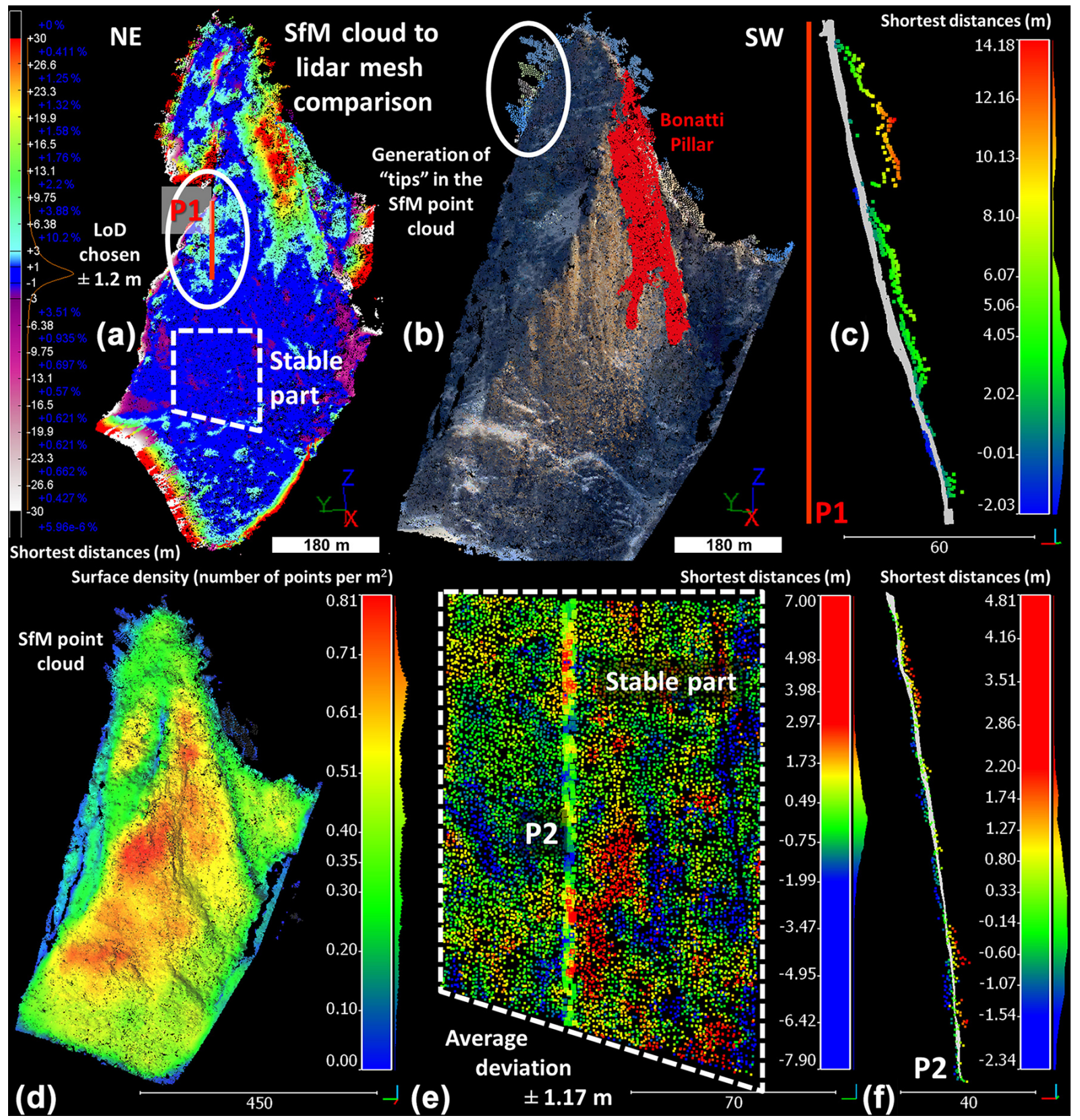

Figure 3. SfM-lidar comparison. (a) Result of the point-to-mesh comparison between the SfM point cloud and the reference lidar mesh. The color scale of the shortest distances is divided into two parts: positive deviations from blue to red and negative deviations from blue to white. (b) SfM point cloud of the Drus with, in red, the positive deviations extracted from the comparison and associated with the Bonatti Pillar collapse. The two white ellipses illustrate the artifacts that form "tips" in the SfM model, and the red line located in the center of the left ellipse corresponds to the longitudinal cross section P1 that passes through the lidar mesh and the SfM point cloud. This cross section is visible in (c), where the grey points correspond to the lidar mesh, while the colored points come from the SfM model. (d) Point density map of the SfM model (number of points per square meters). (e) Point-to-mesh deviations observed in the stable area framed in (a) with the localization of the longitudinal cross section P2 (highlighted points). This cross section is visible in (f), where the grey points correspond to the lidar mesh, while the colored points come from the SfM model. 


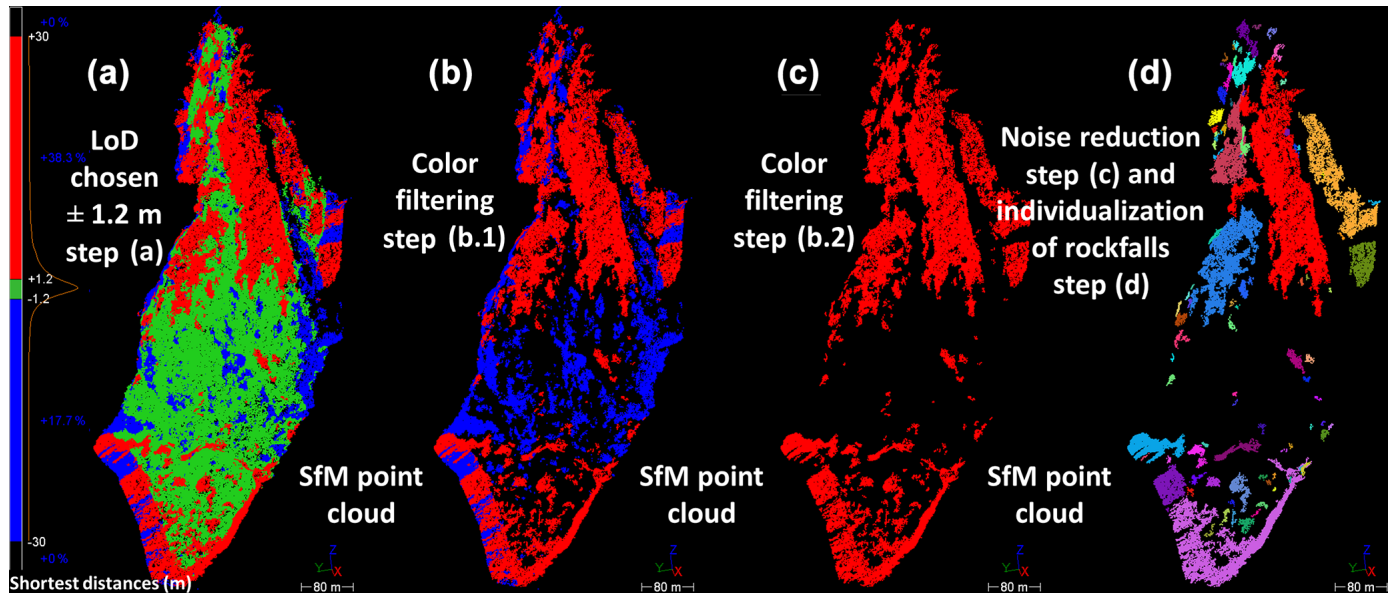

Figure 4. Rockfall extraction method. (a) Result of the point-to-mesh comparison between the SfM point cloud and the reference lidar mesh. Same result as in Fig. 3a but displayed with three colors and a LoD of $\pm 1.2 \mathrm{~m}$. Red color: positive deviations; green color: points between $\pm 1.2 \mathrm{~m}$; and blue color: negative deviations. (b) Filtering of the green color (first step). (c) Filtering of the blue color (second step). (d) Rockfall extraction and individualization. Each color corresponds to an individual point cloud. The points associated with the Bonatti Pillar collapse are highlighted in red.

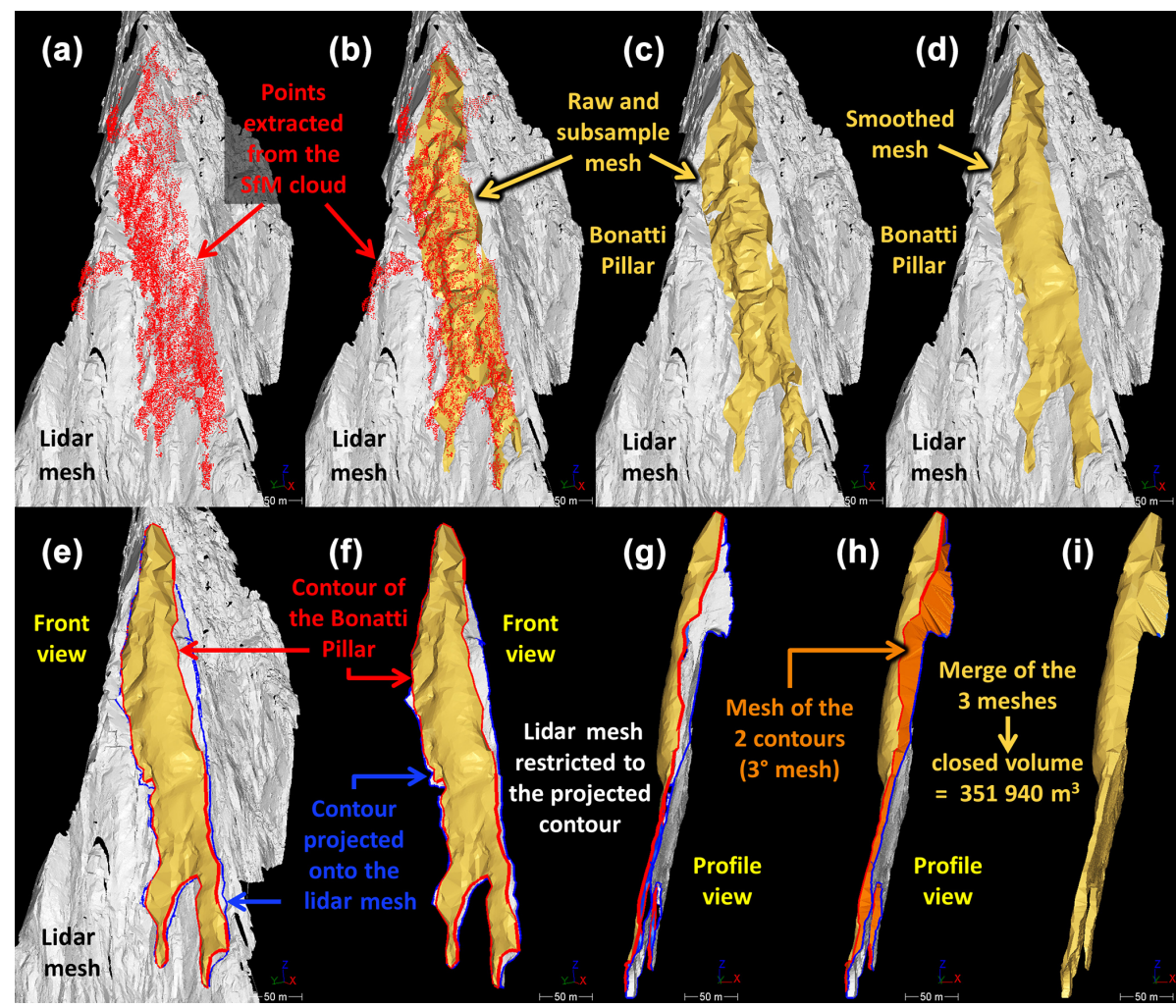

Figure 5. Volume calculation method. (a) Front view of the lidar mesh with the extracted SfM points highlighted in red in Fig. 4d and associated with the Bonatti Pillar collapse. (b) Same image as before but with the raw and subsample SfM mesh. (c) Front view of the lidar mesh with the raw and subsample SfM mesh. (d) Front view of the lidar mesh with the smoothed SfM mesh. (e) Same image as before but with the contour (in red) of the smoothed SfM mesh and the contour (in blue) orthogonally projected onto the lidar mesh. (f) Front view of the smoothed SfM mesh, its contour and the projected contour that allowed cutting the lidar mesh. (g) Profile view of the smoothed SfM mesh, its contour and the projected contour that allowed cutting the lidar mesh. (h) Same image as before but with the third mesh (in orange) that connects the two contours. (i) Profile view of the volume that collapsed between June 2005 and November 2011. 

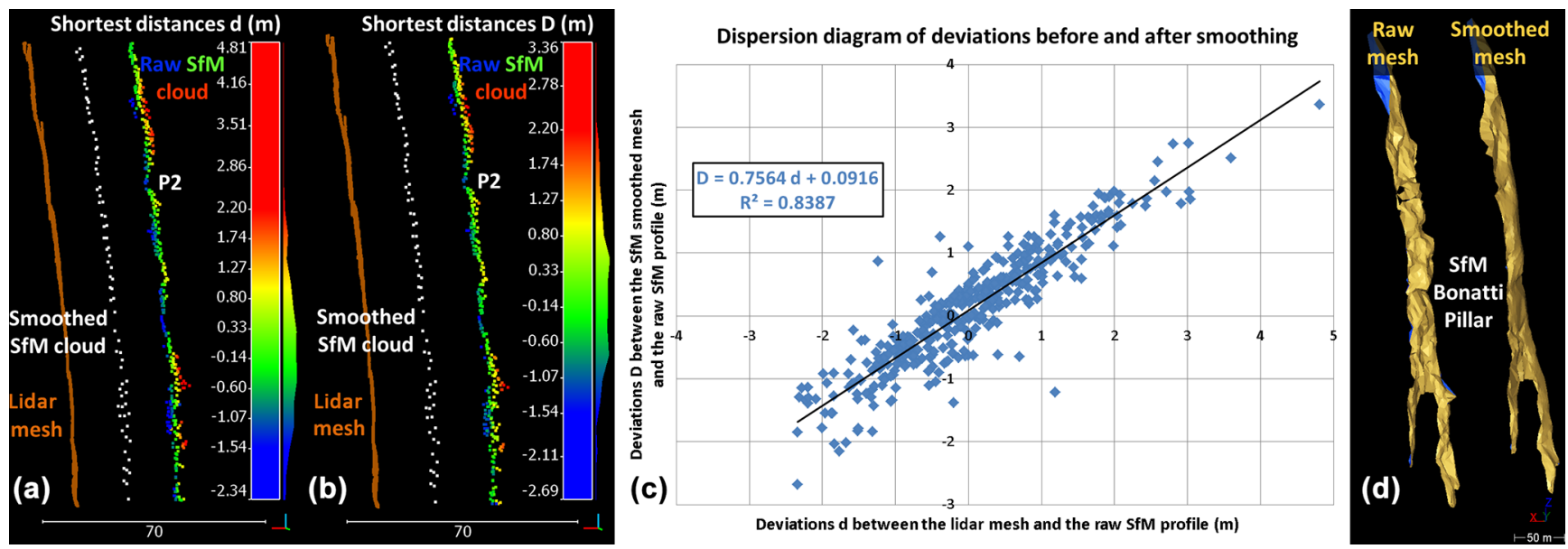

Figure 6. Smoothed data vs. raw data. (a) Result of the point-to-mesh comparison between the raw SfM profile P2 (colored points) and the reference lidar mesh (in brown). Same result as in Fig. $3 \mathrm{f}$ but with the subsample and smoothed SfM profile P2 (in white). The three entities were shifted in order to better display the differences between each profile. (b) Result of the point-to-mesh comparison between the raw SfM profile P2 (colored points) and the subsample and smoothed SfM profile P2 (in white). (c) Dispersion diagram characterizing the SfM point cloud smoothing procedure: minimization of large deviations and reduction of the average deviation by $\pm 0.76 \mathrm{~m}$. (d) Profile view of the raw and smoothed SfM meshes present in Fig. 5c and d.

two other SfM models by importing 84 and $67 \%$ of the pictures used to construct the first point cloud.

\section{Results and discussion}

The comparison between the SfM point cloud and the lidar mesh of 2005/2011 gives a volume of $351940 \mathrm{~m}^{3}$ (Fig. 7a and b). As specified in Sect. 2.3, this volume includes the rockfall events that occurred in September and October 2011, and we had to subtract $59260 \mathrm{~m}^{3}$ (Fig. 7d) from this value to properly assess the June 2005 rock avalanche volume. Therefore, the final value is equal to $292680 \mathrm{~m}^{3}$, which is quite close to the $265000 \pm 10000 \mathrm{~m}^{3}$ (i.e., $\pm 3.8 \%$ ) estimated by Ravanel and Deline (2008) since the uncertainty on the thickness of the estimated volume $( \pm 0.41 \mathrm{~m})$ which arises from all steps of the data processing (scaling and alignment by parts, SfM point cloud subsample and mesh smoothing) gives an error range equal to $\pm 16400 \mathrm{~m}^{3}$ (i.e., $\pm 5.6 \%$ ). Furthermore, the volumes estimated with the two other SfM models are equal to 311970 and $326240 \mathrm{~m}^{3}$. Thus, if we consider the volume of $292680 \mathrm{~m}^{3}$ as the most reliable estimation, the relative error between the three SfM models (related only to the SfM method itself) is respectively equal to \pm 6.6 and $\pm 11.5 \%$. Given the large difference of density of points observed between the SfM model and the lidar point cloud (about 500 times higher for the lidar), this uncertainty value is acceptable and consistent (same order of magnitude) with the one linked to the whole data processing and the one given by Ravanel and Deline (2008).

The lower density of points $\left(0.65\right.$ points $\left.\mathrm{m}^{-2}\right)$ of the SfM cloud is also found in the overall shape of the calculated vol- ume, which is quite rounded (Fig. 7a) and lacks morphological details such as overhangs visible in the upper part of the Bonatti Pillar (Fig. 1d). This lack of details is due not only to the medium resolution of the images that we used to generate the SfM model and the fact that most of the photographs were taken far from the face (Fig. 2) but also to the smoothing procedure, which has clearly rounded the corners and edges of the SfM mesh. However, this step was necessary to minimize the undulation effect observed in the SfM point cloud and, thus, significantly reduce the uncertainty on the depth of the estimated volume. Note that without this smoothing stage the volume estimated for the Bonatti Pillar collapse reaches a value of $353800 \mathrm{~m}^{3}$, which is characterized by a relative error of $\pm 20.9 \%$, only related to the scaling-alignment procedure and the fact that no ground control points were imposed during the SfM point cloud generation. On the other hand, the rounded shape of the volume determined from the SfMlidar comparison suggests that the $292680 \mathrm{~m}^{3}( \pm 5.6 \%)$ calculated could be overestimated. The results shown in Fig. 3a and $\mathrm{b}$ head in this direction since the large positive deviations observed inside the white ellipses do not correspond to rockfall events (verified on pictures) but to artifacts that form "tips" in the SfM point cloud. These tips are clearly visible on the longitudinal profile that passes through the lidar and SfM point clouds in Fig. 3c and also present within the raw points assigned to the Bonatti Pillar collapse (Figs. 5a and $6 \mathrm{~d}$ ). Fortunately, the smoothing of the raw and subsample SfM mesh enabled minimizing these large deviations. These local deformations are certainly linked to the fact that the selected images were taken in different seasons, with different lighting-shading conditions, and with different cameras, and their resolution is quite variable (Fig. 2). 


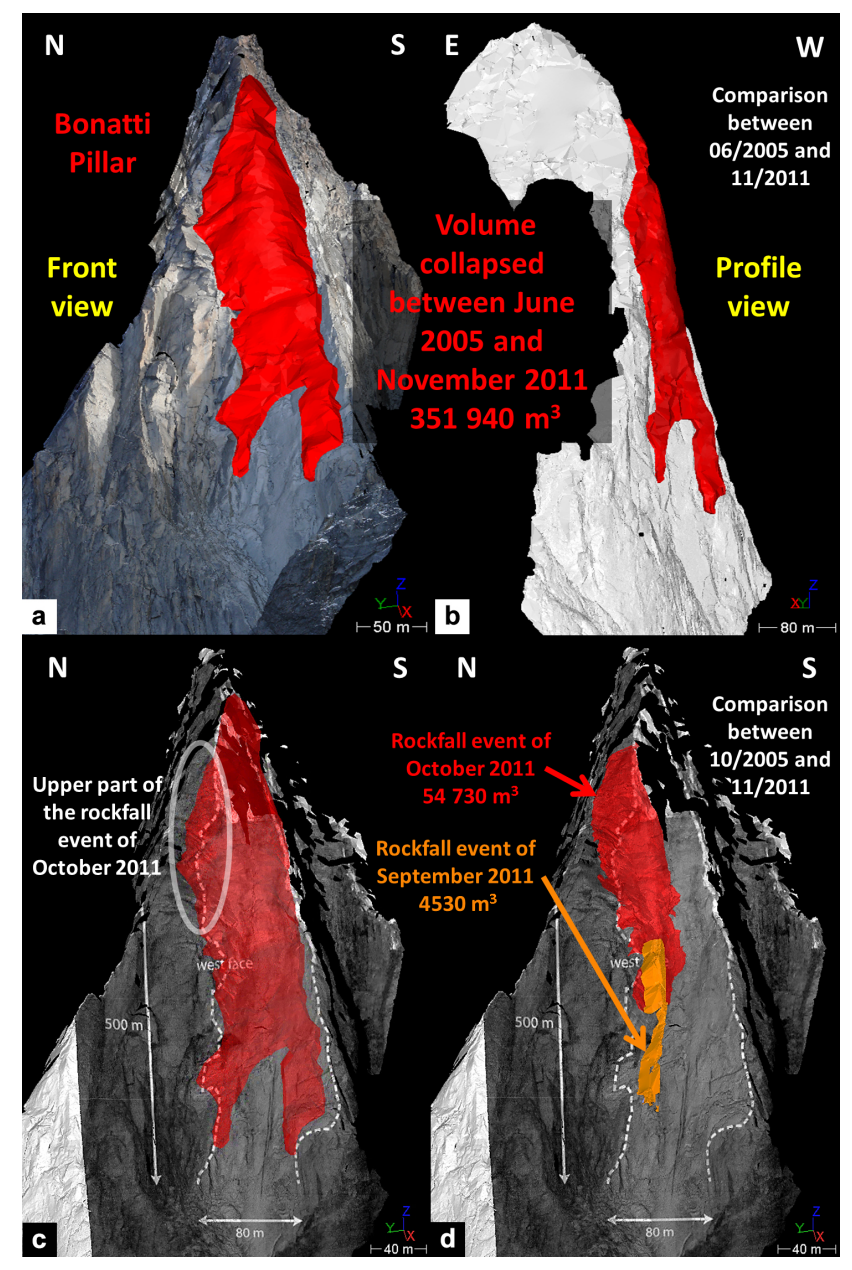

Figure 7. 3-D geometry of the volumes that collapsed between June 2005 and November 2011. (a) Photorealistic model of the Drus west face (high-resolution lidar mesh textured with a picture of November 2011) and front view of the volume (in red) calculated with 3DReshaper. (b) Profile view of the high-resolution lidar mesh (non-textured) as well as the volume shown in Fig. 4a. (c) Superimposition of the volume that collapsed between June 2005 and November 2011 with another photorealistic model, textured from the left part of the Fig. 8 of Fort et al. (2009). The white dashed line shows the scar limits of the June 2005 rock avalanche, and the white ellipse illustrates the area that corresponds to the upper part of the October 2011 rockfall event. (d) Superimposition of the rockfall events that occurred in September (in orange) and October 2011 (in red) with the same photorealistic model as before.

In contrast, we could reproduce accurately the lateral boundaries of the collapsed volume as well as the height of the Bonatti Pillar. Figure 7c perfectly illustrates this aspect since the June 2005 rock avalanche volume exceeds only in one place (at the top left) the scar limits (white dashed line) defined by Fort et al. (2009). Furthermore, this difference was expected because this area corresponds to the upper left part of the October 2011 rockfall event (Fig. 7d). However in this work, we were not looking for a highly accurate volume but rather to assess the potential of merging ground-based lidar acquisitions with terrestrial SfM made from Web-retrieved images for quantifying past natural disasters. With this in mind, it was possible to define a range of relative error for the volume calculation according to the number of pictures used to generate the SfM model: $10.4 \%$ in the case of 30 pictures (difference of $27680 \mathrm{~m}^{3}$ between the volume of $292680 \mathrm{~m}^{3}$ and the reference value of $265000 \mathrm{~m}^{3}$, chosen because of its lower uncertainty range: $\pm 3.8 \%$ ) and $23.1 \%$ with 20 pictures (difference of $61240 \mathrm{~m}^{3}$ compared to $265000 \mathrm{~m}^{3}$ ). This suggests that the accuracy of the volume could have been improved if more than 30 images had been available. Note that these error percentages could have been higher if the LoD chosen $( \pm 1.2 \mathrm{~m}$ in our case) had been lower (e.g., $\pm 1 \mathrm{~m}$ ) since more points would have been extracted from the comparison and associated with the volume of the June 2005 rock avalanche. Nevertheless, it is not excluded that the volume determined by Ravanel and Deline in 2008 is slightly underestimated because, even if accurate measurements were performed on the lidar mesh of October 2005, there is no 3-D model available before the collapse. For such volume ranges, it is often the thickness that is difficult to correctly assess, and a small variation (e.g., $15 \mathrm{~cm}$ ) can modify the final result by several thousands of cubic meters. In the specific case of the Bonatti Pillar ( $500 \mathrm{~m}$ high and $80 \mathrm{~m}$ wide), a depth variation of $1 \mathrm{~m}$ could change the final volume by about $40000 \mathrm{~m}^{3}$. Finally, it is important to specify that both volumes that fell in September and October 2011 play a significant role in our estimations. However, given the uncertainties mentioned in Sect. 2.3 - the volumes were calculated by comparing the October 2005 lidar point cloud of the Flammes de Pierre to the November 2011 lidar triangular mesh of the Drus glacier - the values are pretty accurate, and it is not these estimations that most influence the final result.

\section{Conclusion}

The method described in this brief communication has worked remarkably well for the Petit Dru west face, which is a legendary peak that has been photographed for decades and from several corners of the Chamonix-Mont Blanc valley. However, it is important to highlight that the same method would have been difficult to implement on a lesswell-known site, where fewer images could have been collected and downloaded from picture-hosting services on the World Wide Web. Another issue may be the limited number of viewpoints that exist at a study site because it is necessary to rotate around the area of interest to create a good-quality SfM model. In the field of natural hazards, digitization of old photographs coupled with SfM methods is to be taken into account because it can deliver extremely useful data on the morphologies of the past. In some cases, this could allow going back to the beginning of the last century and even to 1860 
for the Drus with the different photographs (daguerreotypes) of the Bisson brothers, two pioneers of French photography.
Data availability. Since the data sets presented in this brief communication were the results of different agreements between private and academic partners, they are subjected to availability restrictions and are not public. 


\section{Appendix A: Photo credits}

As specified in the acknowledgements, we thank Flickr users Nick Wotherspoon, Rob Fisher, Chris E. Rushton, Paul Liley, "::Olivier:.", François Dorothé, "bengalmixer", Helmuth Van Pottelbergh, John Rule and "JD-Davis", and SummitPost users "mountaindog", "om", "alex2002", "VerseVend", "davis 13" and "isai" for allowing us to reproduce their photographs. Furthermore, we also acknowledge the following Flickr and Camptocamp users whose photographs have been reproduced under Creative Commons licenses (https: //creativecommons.org/licenses/): Mark Horrel (CC BY-NCSA 2.0), "phileole" (CC BY 2.0), David Dufresne (CC BYND 2.0) and "Jimi Hendrix" (CC BY-SA 2.0). Below is a list of citations and links to the 30 Web-retrieved images that were downloaded from the three following websites: Flickr.com, SummitPost.org and Camptocamp.org (classification by website and chronological order).

\section{Flickr.com (16)}

- Mark Horrel: "Les Drus (3754 m), seen from the Mer de Glace", 11 August 2003, online image, License CC BY-NC-SA 2.0, available at: https://www.flickr.com/ photos/markhorrell/17225632811.

- Nick Wotherspoon: "Les Drus", 24 August 2003, online image, all rights reserved, available at: https://www. flickr.com/photos/42624864@N08/5765604229.

- "phileole": "Vallée de Chamonix", 24 December 2003, online image, License CC BY 2.0, available at: https: //www.flickr.com/photos/phileole/520390144.

- "phileole": "Vallée de Chamonix", 24 December 2003, online image, License CC BY 2.0, available at: https: //www.flickr.com/photos/phileole/520418709.

- "phileole": "Vallée de Chamonix", 24 December 2003, online image, License CC BY 2.0, available at: https: //www.flickr.com/photos/phileole/520419341

- Rob Fisher: "Le Petit Dru", 3 July 2004, online image, all rights reserved, available at: https://www.flickr.com/ photos/robonabike/4568776704.

- Chris E. Rushton: “The Dru, (Les Drus) Chamonix”, 20 July 2004, online image, all rights reserved, available at: https://www.flickr.com/photos/mvcchris/9697023856.

- Paul Liley: "The Dru-Chamonix Valley", 8 August 2004, online image, all rights reserved, available at: https://www.flickr.com/photos/paulliley/4965510586/.

- “.:Olivier:.”: "Les Drus", 19 August 2004, online image, all rights reserved, available at: https://www.flickr. com/photos/29922628@N08/3192264930.
- François Dorothé: "Les Drus, Chamonix", $21 \mathrm{Au}-$ gust 2004, online image, all rights reserved, available at: https://www.flickr.com/photos/francoisdorothe/ 5451738425.

- David Dufresne: "Les Drus - 3754 m", 26 October 2004, online image, License CC BY-ND 2.0, available at: https://www.flickr.com/photos/davduf/1075398.

- "bengalmixer": "drusdrusdrus", 9 November 2004, online image, all rights reserved, available at: https://www. flickr.com/photos/bengalshare/952842570.

- Helmuth Van Pottelbergh: "Les Drus, face ouest du Petit Dru at Chamonix, France", 31 December 2004, online image, all rights reserved, available at: https://www. flickr.com/photos/tsa-climbing/6505792537.

- John Rule: “Les Drus”, 11 January 2005, online image, all rights reserved, available at: https://www.flickr.com/ photos/ebbandflow/4501086770.

- John Rule: “Les Drus", 13 January 2005, online image, all rights reserved, available at: https://www.flickr.com/ photos/ebbandflow/4500495087.

- "JD-Davis": "Ledrucloser", 1 May 2005, online image, all rights reserved, available at: https://www.flickr.com/ photos/jd-davis/15930404616.

\section{SummitPost.org (13)}

- "mountaindog": "The Dru as seen from the Gran Balcon Nord Trail", fall 2003, online image, all rights reserved, available at: http://www.summitpost. org/the-dru-as-seen-from-the-gran/40929/c-150757.

- "om": "Aiguille Verte, Drus, Flammes de pierre. West side. 12/2004", December 2004, online image, all rights reserved, available at: http://www.summitpost. org/aiguille-verte/84226/c-183839.

- "om": "Aiguille Verte at sunset. 12/2004", December 2004, online image, all rights reserved, available at: http://www.summitpost.org/aiguille-verte/ $84227 / \mathrm{c}-183839$.

- "alex2002": "At sunset in Winter", January 2005, online image, all rights reserved, available at: http://www. summitpost.org/at-sunset-in-winter/85906/c-1507577.

- "VerseVend": "Aiguille du Dru from Brevent", January 2005, online image, all rights reserved, available at: http://www.summitpost.org/ aiguille-du-dru-from-brevent/86618/c-150757.

- "davis13": "Les Drus from Mere de Glace", April 2005, online image, all rights reserved, available at: http: //www.summitpost.org/les-drus-from-mere-de-glace/ 116269/c-150757. 
- "om": "Aiguille du Dru north face", June 2005, online image, all rights reserved, available at: http://www. summitpost.org/aiguille-du-dru/112230/c-182555.

- "om": "Aiguille du Dru: the gray rocks is the place where huge stone falls append", June 2005, online image, all rights reserved, available at: http://www. summitpost.org/aiguille-du-dru/112906/c-182555.

- "om": "Aiguille du Dru and Flammes de Pierre", June 2005, online image, all rights reserved, available at: http://www.summitpost.org/ aiguille-du-dru-flammes-de-pierre/112907/c-182555.

- "om": "Petite Aiguille Verte, Aiguille Verte NW side, Aiguille du Dru. Charpoua Glacier, 06/2005", June 2005, online image, all rights reserved, available at: http://www.summitpost.org/aiguille-verte/112911/ c- 182555 .
- "isai": "Les Drus By Sjaak de Visser", June 2005, online image, all rights reserved, available at: http: //www.summitpost.org/les-drus-by-sjaak-de-visser/ $108214 / \mathrm{c}-150757$

- "isai": "Petit Dru", June 2005, online image, all rights reserved, available at: http://www.summitpost. org/petit-dru/108236/c-150757.

- "isai": "Petit Dru", June 2005, online image, all rights reserved, available at: http://www.summitpost. org/petit-dru/108291/c-150757.

\section{Camptocamp.org (1)}

- "Jimi Hendrix": "Ca tombe Dru ce 29 Juin 2005...”, 29 June 2005, online image, License CC BY-SA 2.0, available at: https://www.camptocamp.org/images/239435/ fr/ca-tombe-dru-ce-29-juin-2005. 
Competing interests. The authors declare that they have no conflict of interest.

Acknowledgements. The authors would like to acknowledge the Swiss National Science Foundation (SNSF, grants 200020_146426 and 200020_159221) for supporting this research. The second author was granted a Marie Curie fellowship (project ref.: 705215). In addition, we would like to thank the authors of the pictures extracted from Flickr, SummitPost and Camptocamp (see Appendix A for a detailed description) and also express our appreciation for the support of the Chamonix Mont-Blanc Helicopters (CMBH) company for reaching the stations from which terrestrial lidar acquisitions were performed. Finally, special thanks go to JeanLuc Epard for his explanations concerning the interpretation of the geotectonic setting of Mont Banc massif.

Edited by: Oded Katz

Reviewed by: two anonymous referees

\section{References}

Abellán, A., Derron, M. H., and Jaboyedoff, M.: Editorial: "Use of 3-D Point Clouds in Geohazards" Special Issue: Current Challenges and Future Trends, Remote Sens., 8, 130, https://doi.org/10.3390/rs8020130, 2016.

AgiSoft, L. L. C.: Agisoft PhotoScan Professional Edition (version 1.0.3), available at: http://www.agisoft.com/, 2014.

Bakker, M., and Lane, S. N.: Archival photogrammetric analysis of river-floodplain systems using Structure from Motion (SfM) methods, Earth Surf. Proc. Land., 42, 1274-1286, https://doi.org/10.1002/esp.4085, 2016.

Besl, P. J. and McKay, N. D.: Method for registration of 3-D shapes, in: Robotics-DL tentative, Int. Soc. Opt. Photon., 586-606, 1992.

Bussy, F., Schaltegger, U., and Marro, C.: The age of the MontBlanc granite (Western Alps): a heterogeneous isotopic systeme dated by $\mathrm{Rb}$-Sr whole rock determinations on its microgranular enclaves, Schweiz. Miner. Petrog., 69, 3-13, 1989.

Byers, S. and Raftery, A. E.: Nearest-neighbor clutter removal for estimating features in spatial point processes, J. Am. Stat. Assoc., 93, 577-584, 1998.

Doulamis, A., Ioannides, M., Doulamis, N., Hadjiprocopis, A., Fritsch, D., Balet, O., Julien, M., Protopapadakis, E., Makantasis, K., Weinlinger, G., Johnsons, P. S., Klein, M., Fellner, D., Stork, A., and Santos P.: 4D reconstruction of the past, in: First International Conference on Remote Sensing and Geoinformation of Environment, Int. Soc. Opt. Photon., 87950J-87950J, 2013.

Egli, D. and Mancktelow, N.: The structural history of the Mont Blanc massif with regard to models for its recent exhumation, Swiss J. Geosci., 106, 469-489, 2013.

Eltner, A., Kaiser, A., Castillo, C., Rock, G., Neugirg, F., and Abellán, A.: Image-based surface reconstruction in geomorphometry - merits, limits and developments, Earth Surf. Dynam., 4, 359389, https://doi.org/10.5194/esurf-4-359-2016, 2016.

Epard, J.-L.: La nappe de Morcles au sud-ouest du Mont-Blanc, Mémoires de Géologie (Lausanne), Thèse de doctorat, 8, 165 pp., 1990.
Ester, M., Kriegel, H. P., Sander, J., and Xu, X.: A density-based algorithm for discovering clusters in large spatial databases with noise, in: Kdd, 96, 226-231, 1996.

Estrin, J.: In an Age of Likes, Commonplace Images Prevail, The New York Times' Lens Blog, 2012.

Firpo, G., Salvini, R., Francioni, M., and Ranjith, P. G. Use of digital terrestrial photogrammetry in rocky slope stability analysis by distinct elements numerical methods, Int. J. Rock Mech. Min. Sci., 48, 1045-1054, 2011.

Fonstad, M. A., Dietrich, J. T., Courville, B. C., Jensen, J. L., and Carbonneau, P. E.: Topographic structure from motion: a new development in photogrammetric measurement, Earth Surf. Proc. Land., 38, 421-430, 2013.

Fort, M., Cossart, E., Deline, P., Dzikowski, M., Nicoud, G., Ravanel, L., Schoeneich, P., and Wassmer, P.: Geomorphic impacts of large and rapid mass movements: a review, Groupe français de géomorphologie, 15, 47-64, 2009.

Furukawa, Y., Curless, B., Seitz, S. M., and Szeliski, R.: Towards internet-scale multi-view stereo, 2010 IEEE Conference on Computer Vision and Pattern Recognition (CVPR), 14341441, 2010.

Girardeau-Montaut, D.: CloudCompare (version 2.7), GPL software, EDF RandD, Telecom ParisTech, available at: http://www. cloudcompare.org, 2015.

Grün, A., Remondino, F., and Zhang, L.: Photogrammetric reconstruction of the great Buddha of Bamiyan, Afghanistan, Photogramm. Rec., 19, 177-199, 2004.

Grün, A., Remondino, F., and Zhang, L.: The Bamiyan project: multi-resolution image-based modeling, Recording, Modeling and Visualization of Cultural Heritage, 415, 45-54, 2005.

Ioannides, M., Hadjiprocopi, A., Doulamis, N., Doulamis, A., Protopapadakis, E., Makantasis, K., Santos, P., Fellner, D., Stork, A., Balet, O., Julien, M., Weinlinger, G., Johnson, P. S., Klein, M., and Fritsch, D.: Online 4D Reconstruction Using Multi-Images Available Under Open Access, ISPRS Ann. Photogramm. Remote Sens. Spatial Inf. Sci., II-5/W1, 169-174, oi:10.5194/isprsannals-II-5-W1-169-2013, 2013.

James, M. R. and Robson, S.: Mitigating systematic error in topographic models derived from UAV and ground-based image networks, Earth Surf. Proc. Land., 39, 1413-1420, 2014.

Kyriakaki, G., Doulamis, A., Doulamis, N., Ioannides, M., Makantasis, K., Protopapadakis, E., Hadjiprocopis, A., Wenzel, K., Fritsch, D., Klein, M., and Weinlinger, G.: 4D Reconstruction of Tangible Cultural Heritage Objects from Web-Retrieved Images, Int. J. Heritage Digital Era, 3, 431-451, 2014.

Lucieer, A., de Jong, S., and Turner, D.: Mapping landslide displacements using Structure from Motion (SfM) and image correlation of multi-temporal UAV photography, Prog. Phys. Geog., 38, 97-116, 2014.

Matasci, B., Jaboyedoff, M., Ravanel, L., and Deline, P.: Stability Assessment, Potential Collapses and Future Evolution of the West Face of the Drus (3754 m asl, Mont Blanc Massif), in: Engineering Geology for Society and Territory, Springer International Publishing, Vol. 2, 791-795, 2015.

Oikonomidis, D., Albanakis, K., Pavlides, S., and Fytikas, M.: Reconstruction of the paleo-coastline of Santorini island (Greece), after the 1613 BC volcanic eruption: A GIS-based quantitative methodology, J. Earth Syst. Sci., 125, 1-11, 2016. 
Ravanel, L.: Caractérisation, facteurs et dynamiques des écroulements rocheux dans les parois à permafrost du massif du Mont Blanc, Université de Savoie, Thèse de doctorat, 326 pp., 2010.

Ravanel, L. and Deline, P.: Nouvelles méthodes d'étude de l'évolution des parois rocheuses de haute montagne: application au cas des Drus, Proceedings of the workshop "Géologie et Risques Naturels: la gestion des risques au Pays du Mont Blanc", 48-53, 2006.

Ravanel, L. and Deline, P.: La face ouest des Drus (massif du MontBlanc): évolution de l'instabilité d'une paroi rocheuse dans la haute montagne alpine depuis la fin du petit âge glaciaire, Géomorphologie: relief, processus, Environnement, 14, 261-272, 2008.

Salvini, R., Francioni, M., Riccucci, S., Bonciani, F., and Callegari, I.: Photogrammetry and laser scanning for analyzing slope stability and rock fall runout along the Domodossola-Iselle railway, the Italian Alps, Geomorphology, 185, 110-122, 2013.

Santos, P., Serna, S. P., Stork, A., and Fellner, D.: The Potential of 3-D internet in the cultural heritage domain, in: 3-D Research Challenges in Cultural Heritage, Springer Berlin Heidelberg, 117, 2014.

Smith, M. W., Carrivick, J. L., and Quincey, D. J.: Structure from motion photogrammetry in physical geography, Prog. Phys. Geog., 40, 247-275, 2016.

Snavely, N., Seitz, S. M., and Szeliski, R.: Modeling the world from internet photo collections, Int. J. Comput. Vision., 80, 189-210, 2008.

Stathopoulou, E. K., Georgopoulos, A., Panagiotopoulos, G., and Kaliampakos, D.: Crowdsourcing Lost Cultural Heritage, ISPRS Ann. Photogramm. Remote Sens. Spatial Inf. Sci., II-5/W3, 295-300, https://doi.org/10.5194/isprsannals-II-5-W3295-2015, 2015.
Steck, A., Bigioggero, B., Dal Piaz, G. V., Escher, A., Martinotti, G., and Masson, H.: Carte tectonique des Alpes de Suisse occidentale, 1: 100 000, Carte géologique spéciale No. 123., Serv. hydrol. géol. natl. (Berne), 2000.

Steck, A., Epard, J.-L., Escher, A., Gouffon, Y., and Masson, H.: Carte tectonique des Alpes de Suisse occidentale 1:100000, Carte géologique spéciale No. 123, notice explicative, Office féd. Eaux Géologie (Berne), 2001.

Technodigit: 3DReshaper: the 3-D Scanner Software (Version 2014 MR1), Computer software, available at: http://www.3dreshaper. com/, 2014.

Tonini, M. and Abellán, A.: Rockfall detection from terrestrial LiDAR point clouds: A clustering approach using R, J. Spatial Information Science, 2014, 95-110, 2014.

Turner, D., Lucieer, A., and Watson, C.: An automated technique for generating georectified mosaics from ultra-high resolution unmanned aerial vehicle (UAV) imagery, based on structure from motion (SfM) point clouds, Remote Sens., 4, 1392-1410, 2012.

Vincent, M. L., Gutierrez, M. F., Coughenour, C., Manuel, V., Bendicho, L. M., Remondino, F., and Fritsch, D.: Crowd-sourcing the 3-D digital reconstructions of lost cultural heritage, IEEE 2015 Digital Heritage, 1, 171-172, 2015.

von Raumer, J. F. and Bussy, F.: Mont Blanc and Aiguilles Rouges: Geology of Their Polymetamorphic Basement (external Massifs, Western Alps, France-Switzerland), Université de LausanneSection des sciences de la Terre, 2004.

Wujanz, D., Krueger, D., and Neitzel, F.: Identification of Stable Areas in Unreferenced Laser Scans for Deformation Measurement, Photogramm. Rec., 31, 261-280, 2016. 